\title{
Job Scheduling Heuristics and Simulation Tools in Cloud Computing Environment: A Survey \\ Krunal N. Vaghela
}

Research Scholar, School of Engineering, RK University, Rajkot, Gujarat.

Email: krunal.vaghela910@gmail.com

Dr. Paresh J. Tanna

Assistant Professor, School of Engineering, RK University, Rajkot, Gujarat. Email: paresh.rkcet@gmail.com

Dr. Amit M. Lathigara

Associate Professor, Faculty of Engineering, Marwadi University, Rajkot

Email : amit.lathigara@gmail.com

\begin{abstract}
Cloud computing is the extension of distributed computing, grid computing and parallel processing. Cloud Computing Environments provides an efficient way to host, process and analyze large amount of data on remote machines. Apart from this, it also provides various Infrastructure Services (IAAS), Software Services (SAAS) and Platform Services (PAAS) for hosting purpose. Various job scheduling heuristics are proposed over the time for efficient execution of various jobs in Cloud environment. Efficient scheduling of jobs is key factor on performance enhancement of Scheduling Heuristics. Various performance parameters like completion time, waiting time, success rate, resource utilization etc. are used to measure performance of various heuristics. These parameters are also used to measure Quality of Service (QoS) that these heuristics provides to bunch of jobs. Here a detailed survey of various job scheduling heuristics and various simulation tools which are used for simulation of these heuristics is presented. Main objective of this survey paper is to present a detailed survey of various job scheduling heuristics available and different simulation tools available to simulate these heuristics in Cloud environment. A detailed comparative analysis is present for various job scheduling heuristics available and different simulation tools.
\end{abstract}

Keywords - Cloud Computing, Scheduling Heuristics, Quality of Service (QoS), Cloud Simulators

Date of Submission: May 22, 2018

Date of Acceptance: July 17, 2018

\section{INTRODUCTION}

Cloud computing is a recent trend in IT which provide various services like Infrastructure Services (IAAS), Software Services (SAAS) and Platform Services (PAAS). A general architecture of Cloud Computing is shown in Fig. 1. With help of Cloud Computing, user can extend computational power and storage capacity of machine. Cloud provides a convenient environment for resources which is used by multiple cloud users. Customers can use any software or hardware without purchasing for it. Client only needs a machine with internet connection that's it. Main idea is to use unutilized infrastructure at nominal cost.

Scheduling jobs in efficient manner is very crucial in Cloud computing environment, because cloud service providers must satisfy various needs of many cloud users. There are various ways to categorize scheduling heuristics. One category is task scheduling, workflow scheduling, resource scheduling, job scheduling etc. It is also categories as Static Scheduling and Dynamic Scheduling. In static scheduling, execution of jobs is fixed before starting, while in dynamic scheduling, jobs are scheduled as it arrives.

Providing Quality of Service(QoS) and satisfy various needs of users is very challenging in cloud environment. Different users are having different QoS requirements.
Various applications also demand varying services. So, with virtualized cloud resources, it becomes very challenging to satisfy requirements of each users and applications as well.

For real use of the unbelievable abilities of the Cloud, effective scheduling heuristics are needed. Main goal of such algorithms is to minimize total execution time by allocating best resource for the job. It is not like that every time reduction in total execution time results in reduction of execution time of each individual job.

The remaining paper is prepared as follows. Part II presents existing scheduling algorithms. Part III presents various simulations tools available for simulations of scheduling heuristics and part IV contains conclusion and contributions of authors.

\section{EXISTING SCHEDULING ALGORITHMS}

Following scheduling algorithms are currently widespread in clouds.

XiaoShan He, Xianhe Sun and Gergor von Laszewski [3] in 2003 suggested a QoS Guided Min-Min heuristic which focuses on varying bandwidth requirement of various jobs. In this algorithm matching between QoS requirement of users and provided service are based on conventional Min-Min. Main focus is on one-dimensional Quality of Service issue here. 
Dong. F, Luo. J, Gao. L and Ge. L. [4] in 2006 proposed a QoS priority grouping algorithm which focuses on deadline and acceptation rate of the job \& makespan as key factor of job scheduling in whole system. Results are better than Min-Min and Qos Guided Min-Min as far as completion time and acceptance rates are concerned.

M. Singh and P.K. Suri [5] in 2008 proposed a QoS based predictive Max-Min, Min-Min switcher heuristic. In this heuristic focus is on scheduling of the next job depends on suitable assortment among QoS based minmin or QoS max-min heuristic. Past of task execution is used to forecast performance of resource. This heuristic merge the effectiveness of max-min along with min-min.

Saeed Parsa and Reza Entezari - Maleki [6] in 2009 developed a new task scheduling algorithm called RASA which has the advantage of both Min-Min and Max-Min algorithms. In RASA, completion task of job is estimated on each resource and then both algorithms are applied. RASA use the Min-Min policy to implement the small job first then long job and then applied Max-Min to duck the interruptions in the implementation of large job and support concurrency in the implementation of the big and small jobs.

Huifang Li, Siyuan Ge, Lu Zhang [7] in 2014 established a QDA scheduling heuristic using cloud workflow as a background. It works on instance-intensive workflow scheduling optimization problem. It takes many Quality of Service parameters in to consideration like time, cost, bandwidth, reliability, enumerates them with value and use them in Quality of Service based subdeadline distribution heuristic to meet whole Quality of Service user satisfaction.

Hilda Lawrance and Dr. Salaja Silas [8] in 2013 suggested a job-based scheduling of resources named potentially all pair-wise rankings of all possible alternatives (PAPRIKA). It counts different Quality of Service parameters in to account and resources are planned according to user requirement and PAPRIKA method.

Mrs. S. Selvarani, Dr. G. Sudha Sadhasivam [9] in 2010 suggested a better cost-based scheduling heuristic to make effective mapping of jobs to accessible resources in Cloud. Heuristic divisions all user jobs depending on importance of each job into 3 different lists. This job scheduling heuristic focus on resource cost and calculation performance both, it also enhances the calculation/communication ratio.

Cui Lin, Shiyong Lu [10] in 2011 suggested an SHEFT workflow scheduling heuristic for scheduling a workflow elastically on a Cloud Computing platform. Main advantage of this heuristic is it allows resources to scale elastically at runtime.

Meng Xu, Lizhen Cui, Haiyang Wang, Yanbing Bi [11] in 2009 suggested a numerous workflows and numerous
Quality of Service. Main working of this heuristic is on multiple workflow management system with multiple Quality of Service. This strategy minimizes the makespan and cost of workflows in Cloud Computing environment.

Comparison of Various Scheduling Heuristics is given in Table 1.

\section{CLOUD SIMULATION TOOLS}

Cloud resources are costly and cost of setting actual cloud environment is also high. Small scale organizations and researchers may not go with actual cloud implementation for their experiments in cloud environment. They would mostly prefer various simulators available in market for simulation of cloud environment. The use of simulation tools leads to decrease in overall operational cost of the organizations. There are various benefits of using simulators like no capital cost involved, generation of better results, evaluation of various risks on early stage, easy to learn etc. Brief description of few Cloud simulators is given in Table 2 .

\section{FIGURES AND TABLES}

\section{Cloud Computing Architecture}

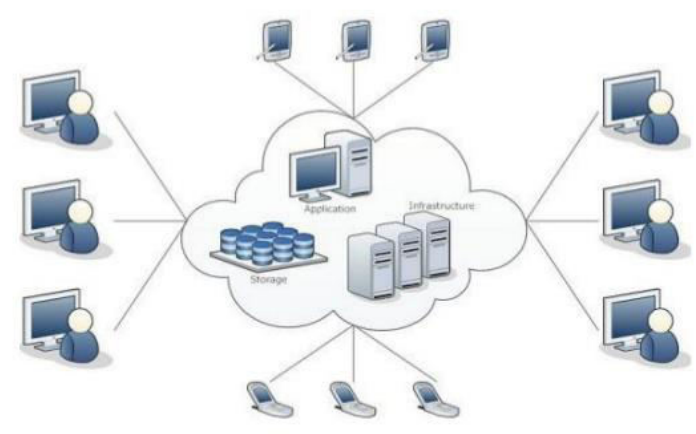

Fig.1. General Architecture of Cloud Computing 


\begin{tabular}{|c|c|c|c|c|}
\hline $\begin{array}{l}\text { Sr. } \\
\text { No }\end{array}$ & $\begin{array}{l}\text { Job Scheduling } \\
\text { Heuristics }\end{array}$ & $\begin{array}{l}\text { Scheduling }(\text { QoS }) \\
\text { Parameters }\end{array}$ & Findings & Tool \\
\hline 1 & $\begin{array}{l}\text { QDA Scheduling } \\
\text { Algorithm [7] }\end{array}$ & $\begin{array}{l}\text { Bandwidth, Time } \\
\text { Reliability, Cost }\end{array}$ & $\begin{array}{l}\text { 1. Better load balancing. } \\
\text { 2. Better Cost. }\end{array}$ & CloudSim \\
\hline 2 & $\begin{array}{l}\text { A Particle Swarm } \\
\text { Optimization-based } \\
\text { Heuristic for } \\
\text { Scheduling [12] }\end{array}$ & $\begin{array}{l}\text { Execution Time, } \\
\text { Resource Utilization }\end{array}$ & $\begin{array}{l}\text { 1. Better Resource Utilization. } \\
\text { 2. Fair workload distribution } \\
\text { among resources. }\end{array}$ & $\begin{array}{l}\text { Amazon Web } \\
\text { Services }\end{array}$ \\
\hline 3 & $\begin{array}{l}\text { Improved Cost } \\
\text { Based Algorithm [9] }\end{array}$ & Latency, makespan & $\begin{array}{l}\text { 1. Better makespan with more } \\
\text { numbers of VMs. } \\
\text { 2. Overall improved latency. }\end{array}$ & CloudSim \\
\hline 4 & $\begin{array}{l}\text { Innovative } \\
\text { transaction intensive } \\
\text { cost-constraint } \\
\text { scheduling } \\
\text { algorithm [13] }\end{array}$ & $\begin{array}{l}\text { Execution Time, } \\
\text { Cost }\end{array}$ & $\begin{array}{l}\text { 1. Lesser cost for few situations } \\
\text { 2. Permits the negotiations of } \\
\text { completing cost and time }\end{array}$ & SwinDeW \\
\hline 5 & $\begin{array}{l}\text { SHEFT workflow } \\
\text { scheduling } \\
\text { algorithm [14] }\end{array}$ & $\begin{array}{l}\text { Execution Time, } \\
\text { Scalability }\end{array}$ & $\begin{array}{l}\text { 1. Optimized Execution Time } \\
\text { 2. Runtime Scaling of } \\
\text { Resources }\end{array}$ & CloudSim \\
\hline 6 & \begin{tabular}{lrr} 
Job & \multicolumn{2}{r}{ Scheduling } \\
based on & Berger \\
Model & {$[15]$} & \\
\end{tabular} & $\begin{array}{l}\text { Job Completion } \\
\text { Time, Fairness }\end{array}$ & $\begin{array}{l}\text { 1. Meeting user's expectations } \\
\text { 2. Better Job Execution Time }\end{array}$ & CloudSim \\
\hline 7 & $\begin{array}{l}\text { Multiple QoS } \\
\text { Constrained } \\
\text { Scheduling Strategy } \\
\text { of Multi-Workflows } \\
{[11]}\end{array}$ & $\begin{array}{l}\text { Makespan, success } \\
\text { rate of jobs, } \\
\text { execution time }\end{array}$ & $\begin{array}{l}\text { 1. Improved job execution time } \\
\text { 2. Dynamic scheduling of jobs }\end{array}$ & CloudSim \\
\hline 8 & $\begin{array}{l}\text { Task scheduling } \\
\text { algorithm based on } \\
\text { QoS-driven in cloud } \\
\text { computing [16] }\end{array}$ & $\begin{array}{l}\text { Total completion } \\
\text { time, Priority }\end{array}$ & $\begin{array}{l}\text { 1. Fair Scheduling for balancing } \\
\text { load } \\
\text { 2. Better performance as far as } \\
\text { total completion task is } \\
\text { concerned }\end{array}$ & CloudSim \\
\hline 9 & PAPRIKA [8] & $\begin{array}{l}\text { Complication Time, } \\
\text { Utility }\end{array}$ & $\begin{array}{l}\text { 1. Enhanced resource utility } \\
\text { 2. Taking less time for task } \\
\text { allocation to resources }\end{array}$ & CloudSim \\
\hline 10 & $\begin{array}{l}\text { Ant Colony } \\
\text { Optimization }(\mathrm{ACO}) \\
{[17]}\end{array}$ & $\begin{array}{l}\text { Execution Time, } \\
\text { Cost }\end{array}$ & $\begin{array}{l}\text { 1. Improved execution time } \\
\text { 2. Enhanced cost as far as } \\
\text { resource utilization is } \\
\text { concerned }\end{array}$ & CloudSim \\
\hline 11 & $\begin{array}{l}\text { Multi } \quad \text { QoS } \\
\text { Scheduling } \\
\text { Algorithm [18] }\end{array}$ & Execution Time & $\begin{array}{l}\text { 1. Improved efficiency up to } \\
\text { some extent. }\end{array}$ & CloudSim \\
\hline
\end{tabular}

Table 1. Comparison of Various Scheduling Heuristics 
Table 2. Comparison of Various Cloud Simulation Tools

\begin{tabular}{|c|c|c|c|c|c|}
\hline $\begin{array}{l}\text { Sr. } \\
\text { No }\end{array}$ & $\begin{array}{c}\text { Cloud Simulation } \\
\text { Tools }\end{array}$ & Availability & Language & Platform & Findings \\
\hline 1 & CloudSim [19] & Open Source & JAVA & $\begin{array}{l}\text { Windows, Linux, } \\
\mathrm{MaC}\end{array}$ & $\begin{array}{l}\text { Allows simulations of Cloud } \\
\text { Environment with very large } \\
\text { scale. User can simulate } \\
\text { various virtual servers, data } \\
\text { centres, clients and also can } \\
\text { simulate customized rules. }\end{array}$ \\
\hline 2 & CloudAnalyst [19] & Open Source & JAVA & $\begin{array}{l}\text { Windows, Linux, } \\
\text { MaC }\end{array}$ & $\begin{array}{lrr}\text { Almost } & \text { same feature } & \text { of } \\
\text { CloudSim. GUI based } \\
\text { simulator. Capability to } \\
\text { describe a simulation with } \\
\text { more configurability and } \\
\text { elasticity }\end{array}$ \\
\hline 3 & GreenCloud [19] & Open Source & $\mathrm{C}++$ & Linux & $\begin{array}{l}\text { Much focus on } \begin{array}{r}\text { Energy } \\
\text { Efficiency. Packet }\end{array} \text { level } \\
\text { simulator for energy }- \text { aware } \\
\text { Cloud Computing data centres } \\
\text { with a emphasis on Cloud } \\
\text { communications. }\end{array}$ \\
\hline 4 & Eucalyptus [19] & Open Source & C/JAVA & Windows, Linux & $\begin{array}{l}\text { Private cloud and compatible } \\
\text { with AWS. is an acronym for } \\
\text { Elastic Utility Computing } \\
\text { Architecture for Linking Your } \\
\text { Programs To Useful Systems }\end{array}$ \\
\hline 5 & Open Cloud [19] & $\begin{array}{l}\text { Membership } \\
\text { Required }\end{array}$ & $\begin{array}{l}\text { Hardware } \\
\text { Based }\end{array}$ & Hardware Based & $\begin{array}{l}\text { It is a set of testing tools which } \\
\text { simulate network traffic for } \\
\text { testing network elements and } \\
\text { services. Used for testing of } \\
\text { various Cloud applications. }\end{array}$ \\
\hline 6 & iCanCloud [19] & Open Source & $\mathrm{C}++$ & Linux & $\begin{array}{l}\text { OMNET++ framework is used. } \\
\text { Current and non-existing } \\
\text { Cloud Computing architectures } \\
\text { may be demonstrated and } \\
\text { simulated. It offers approaches } \\
\text { for gaining the energy } \\
\text { consumption of each hardware } \\
\text { component in Cloud } \\
\text { Computing environment. }\end{array}$ \\
\hline 7 & OpenStack [19] & Open Source & Python & Linux & $\begin{array}{l}\text { Compatible with Amazon Web } \\
\text { Services. OpenStack software } \\
\text { controls large pools of } \\
\text { compute, storage, and } \\
\text { networking resources } \\
\text { throughout a datacentre. }\end{array}$ \\
\hline 8 & Opnet [19] & Paid & $\mathrm{C} / \mathrm{C}++$ & Windows, Linux & $\begin{array}{l}\text { It is a tool to simulate the } \\
\text { behaviour and performance of } \\
\text { any type of network. Restricted } \\
\text { application testing for Cloud }\end{array}$ \\
\hline 9 & MDCSim [20] & Paid & $\mathrm{C}++/ \mathrm{JAVA}$ & Windows, Linux & $\begin{array}{l}\text { It helps in modelling unique } \\
\text { hardware features of diverse } \\
\text { components of a data centre }\end{array}$ \\
\hline
\end{tabular}




\section{CONCluSion}

In this paper various job scheduling heuristics have been studies and analyzed. Main focus is on heuristics which provides Quality of Service (QoS). Various QoS parameters to measure are completion time, waiting time, success rate, resource utilization, makespan, cost etc. It is observed that each heuristic is compromising in some QoS parameters to achieve other parameters. In this paper, various cloud simulation tools are also studied and mentioned. Various simulation tools are used to simulate different Cloud scenarios and environment. Few of them are open source and few of them are proprietary. Different simulators are using different programming language like $\mathrm{C} / \mathrm{C}++/ \mathrm{JAVA}$ and works on different platforms like Windows/Linux/Mac etc.

\section{REFERENCES}

[1] Sujit Tilak, Prof. Dipti Patil, A Survey of Various Scheduling Algorithms in Cloud Environment. International Journal of Engineering Inventions, vol. 1(2), pp. 36-39 (2012).

[2] Dhanmeet Singh Kalra., Mohit Pal Singh Birdi, Differentiating Algorithms of Cloud Task Scheduling Based on various Parameters. IOSR Journal of Computer Engineering, Volume 17(6), pp. $35-38$ (2015).

[3] XiaoShan He,Xianhe Sun and Gergor von Laszewski. QoS guided Min-Min heuristic for grid task scheduling. Journal of Computer Science and Technology, vol. 18(4), p.442-451 (2003).

[4] Dong. F, Luo. J, Gao. L and Ge. L, "A Grid Task Scheduling Algorithm Based on QoS Priority Grouping," In the Proceedings of the Fifth International Conference on Grid and Cooperative Computing (GCC'06), IEEE, 2006.

[5] M.Singh and P.K.Suri; -QPSMax-Min $<>$ Min-Min : A QoS Based Predictive Max-Min, Min-Min Switcher Algorithm for Job Scheduling, in a Grid, International Technology Journal, vol. 7(8), pp. 1176-1181 (2008).

[6] Saeed Parsa and Reza Entezari-Maleki, RASA: A New Task Scheduling Algorithm in Grid Environment, World Applied Sciences Journal vol. 7 (Special Issue of Computer \& IT): pp. 152-160 (2009).

[7] Huifang Li, Siyuan Ge, Lu Zhang "A QoS-based Scheduling Algorithm for Instance-intensive Workflows in Cloud Environment"26th Chinese Control and Decision Conference (CCDC) 978-14799-3708-0/14 IEEE 2014.
[8] Hilda Lawrance, Dr. Salaja Silas, Efficient Qos Based Resource Scheduling Using PAPRIKA Method for Cloud Computing. International Journal of Engineering Science and TechNology (IJEST) vol. 5(3) (2013).

[9] Cui Lin, Shiyong Lu," Scheduling Scientific Work flows Elastically for Cloud Computing" in IEEE 4th International Conference on Cloud Computing, (2011).

[10] Meng Xu, Lizhen Cui, Haiyang Wang, Yanbing Bi, "A Multiple QoS Constrained Scheduling Strategy of Multiple Workflows for Cloud Computing", in 2009 IEEE International Symposium on Parallel and Distributed Processing.

[11] Y. Yang, K. Liu, J. Chen, X. Liu, D. Yuan and H. Jin, An Algorithm in SwinDeW-C for Scheduling Transaction-Intensive Cost-Constrained Cloud Workflows, Proc. of 4th IEEE International Conference on e-Science, 374-375, Indianapolis, USA, December 2008.

[12] C. Lin, S.Lu, "Scheduling Scientific Workflow Elasticity for Cloud Computing", IEEE 4th International Conference on Cloud Computing, pp. 246-247, (2011).

[13] Hongbo Yu, Yihua Lan*, Xingang Zhang, Zhidu Liu, Chao Yin, Lindong Li" Job Scheduling Algorithm In Cloud Environment" International Conference on Computational and Information Sciences IEEE, (2013).

[14] Xiaonian Wu, Mengqing Deng, Runlian Zhang, Bing Zeng, Shengyuan Zhou. A task scheduling algorithm based on QoS-driven in Cloud Computing. Information Technology and Quantitative Management(ITQM2013)., pp.11621169 (2013).

[15] Kapil Kumar, Abhinav Hans, Ashish Sharma, Navdeep Singh, Towards the Various Cloud Computing Scheduling Concerns: A Review, International Conference on Innovative Applications of Computational Intelligence on Power, Energy and Controls with their Impact on Humanity (CIPECH14) 28 \& 29 November (2014).

[16] Wenjuan Li, Qifei Zhang, Jiyi Wu1, Jing Li, Haili Zhao Trust-based and QoS Demand Clustering Analysis Customizable Cloud Workflow Scheduling Strategies IEEE International Conference on Cluster Computing Workshops, (2012).

[17] Mr. Manjunatha S, Mr. Bhanu Prakash and Mr. Balakrishna H M. A Detailed Survey on various Cloud computing Simulators. International Journal 
of Engineering Research, vol. 5(4), p.790-791 (2016).

[18] Praveen Kumar, Anjandeep Kaur Rai. An Overview and Survey of Various Cloud Simulation Tools. Journal of Global Research in Computer Science, vol. 5(1), (2014).

\section{Biographies and Photographs}

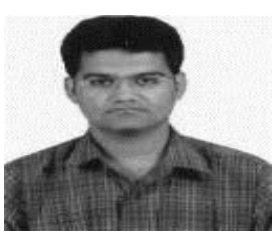

Mr. Krunal Vaghela received the B.E. degree in Computer Engineering from Saurashtra University, Rajkot, in 2004 and Master's Degree from NITTTR Chandigarh in 2014. He is research scholar at Faculty of Technology, RK University, Rajkot, India. After completion of B.E. he worked for many companies as Project Engineer. Since 2009, he is working in Academics and currently he is Assistant Professor in Department of Computer Engineering, Faculty of Engineering at Marwadi Education Foundation Group of Institutions, Rajkot, India.

His areas of interest are Grid Computing, Cloud Computing, Computer Networks, Information Security and Mobile Computing.

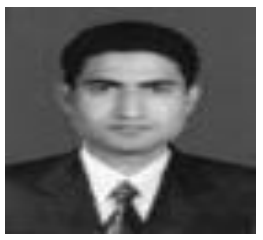

Dr. Paresh Tanna received the M.C.A Degree from IGNOU University with First Class in 2006 and PhD degree in computer science from RK University in 2015. He is currently an Assistant Professor in School of Engineering, RK University, Rajkot. His research interests include Data Mining Algorithms, Big Data Analytics, Data Structure Algorithms, Business Intelligence etc.

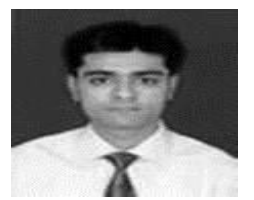

Dr. Amit Lathigara is working as Associate Professor at Marwadi University, Rajkot, India and having extensive teaching experience of more than 13 years. He has completed his master from Anna University, Coimbatore and Ph.D. from RK University. He has written more than 20 research papers published in reputed journals and conference proceedings.

His preliminary research area focuses on routing in Mobile adhoc network and resource and job scheduling under Cloud environment. 